\title{
The Design and Management of the Supervisor Team for Professional Degree Graduate Students under the School-Enterprise Cooperation Model
}

\author{
WANG Xin \\ College of Art Design, Lanzhou Jiaotong University, \\ Lanzhou 730070
}

\begin{abstract}
In this paper, the problems and disadvantages in China's current tutorial system and the objective of training professional degree graduate students are analyzed, and then the graduate student training model under the school-enterprise cooperation model is discussed by combining with the domestic and foreign studies of tutor teams, and finally the construction, management and evaluation index system of a double tutorial system for professional degree graduate students are proposed.
\end{abstract}

Keywords: School-enterprise Cooperation; Professional Degree; Graduate Student Training; Tutor Team

\section{Introduction}

At present, China is in a vigorous development period when postgraduate education develops toward multi-level and multi-type. However, the current training model of colleges and universities seriously hinders the expansion of graduate students' vision on scientific researches, and limits the improvement of the ability to innovate. Thus, the quality of the trained personnel is difficult to meet the needs of the society. To deeply implement the spirit and requirements of the Suggestions on Deepening the Reform of Postgraduate Education (Teaching Research [2013] no.1) issued by the Ministry of Education, the National Development and Reform Commission, and the Ministry of Finance, and the Notice About Carrying Out the
Special Evaluation of the Authorized Centers for Degree in 2014 (degree [2014] no.17) issued by the Academic Degrees Committee of the State Council and the Ministry of Education, the training model joint by schools and practice bases, namely, production-research-learning combination model, is actively promoted according to the characteristics of the professional degree and the actual needs of companies, the state and regions for development, especially the development of major projects. Domestic colleges and universities are trying the best to explore new training mechanism and educational model for professional degree graduate students, in which the most important lies in the change of tutorial system.

\section{The disadvantages of the current tutorial system}

Tutorial system is mainly applied to the training of the graduate students in China's colleges and universities. That is to say, only one supervisor is responsible for guiding graduate students in learning, scientific research, moral character and life, in which the position and role of the supervisor are comprehensive throughout the postgraduate education. Supervisor responsibilities include admitting graduate students, making training plans, implementing course teaching, providing guidance in dissertation and scientific research, and also the care and education for graduate students in ideology, morality, life and so on. 


\subsection{Unable to meet the objective of training professional degree graduate students}

The objective of training professional degree graduate students is greatly different from that of training academic graduate students. For this reason, the state is increasing the proportion of professional degree graduate students in admission year by year, but colleges and universities still continue to use the traditional academic training model in personnel training. Only a few of schools make a small change, but this is unable to meet the needs of training professional degree graduate students fundamentally.

\subsection{Absent care for practice ability training and narrow scope of knowledge}

Now, the graduate student training in most colleges and universities of China is mostly under the guidance of only one supervisor in a traditional sense. That is a training model featuring "master trains an apprentice", and becomes especially prominent in subjects such as architecture, urban and rural planning, landscape architecture, art and design, and the fine arts. The simple training model is beneficial to training elites and inheriting the academic system of supervisor, but it does not consider the individual difference of graduate students, so it goes against the personal cultivation of graduate students. Worse, it is easy to let the learning and research of graduate students marked with the personal academic interests of supervisor, and thus, it is reverse to mobilize the enthusiasm and initiative of graduate students and expand the scope of knowledge. Ultimately, the scientific research view expansion and innovation ability improvement are seriously restricted, and the adaptive capacity can't be promoted. Moreover, the graduate student supervisors in colleges and universities are always busy in personal teaching and subject researches and keep far away from the front lines of engineering projects, production, and construction, so increasingly more disadvantages will be exposed if graduate students are trained for a longer time if the update of knowledge is not stressed by these supervisors.

\section{Exploration on the study of supervisor team}

Domestically, the study of supervisor team is increasingly stressed by many colleges and universities, but the recognition on the positioning and functions of supervisor team is still unclear. In theoretical study, collaborative teaching model incorporating many teachers in a class, research-oriented teaching, optimized teaching methods, course teaching model change, and expert and researcher oriented personnel training are constructed, from which the problems in China's graduate student training are analyzed from different angles. However, the number of graduate students in China's colleges and universities is great and the average penetration of teaching resources is low. Simultaneously, the overall study made by China's colleges and universities is without systematicness and operability in comparison with American colleges and universities which are more successful in innovative personnel training and innovation theory popularity.

At present, a successful exploration and reform model of many foreign colleges and universities in graduate student training is the "guidance system joint by multiple supervisors". European and American universities have made a great achievement in this aspect, and Harvard University is especially a school the most strongly advocating supervisor team training. In this model, a corresponding relationship between supervisor and graduate students is valued, and the students are required to solve more than 800 specific problems about business management during the period of learning and discuss these cases with over 10 multidisciplinary professors together. At the same time, high IQ persons from the business communities must be invited to provide a lecture for students in the classroom. China's Tongji University basically continues to 
use the American graduate student training model integrating supervisors and students in the education practice of garden and landscape graduate students, and advocates the establishment of diversified postgraduate education goals and provides diversified teaching ways for graduate students, so as to meet the need of the development of Chinese landscapes.

\section{The construction of supervisor team}

A good supervisor team is the foundation of postgraduate education, but also the basic guarantee for the teaching work to go smoothly. How to let school-enterprise supervisors effectively combined and give full play to their respective advantages is a guarantee for clearly defining supervisor's power, responsibility and obligation and fully implementing the training model under the guidance of school-enterprise cooperation oriented double supervisor system.

\subsection{Guiding ideology}

The enthusiasm of each training unit and professional practice base must be fully played. Meanwhile, the establishment of school-enterprise jointed training model and the implementation of open graduate student teaching platform's double supervisor system must be conducted. In this process, "improve the consciousness of graduate students in innovation and train innovation ability" is the core, aiming to break the personal dependence relations between graduate students and supervisors, optimize the allocation of resources, define the role positioning of each supervisor, stimulate the enthusiasm and creativity of graduate students and supervisor team, achieve the effective cross between disciplines, and promote the constant improvement of the quality of postgraduate education.

\subsection{Supervisor team design}

\subsubsection{The selection of supervisors}

The scholars and experts, relying on school and practice base, are selected objects. The majors and academic backgrounds contained by professional degree are regarded as the starting point. The senior technical personnel in relevant professions and subjects are appointed as assistants. The combination of theory with practice and the intersection and integration between disciplines are emphasized. From the title of a technical post, different title structure must be considered; from the degree structure, doctor, master, and bachelor must be considered; from the age structure, an echelon construction must be implemented. Thus, a cross-industry complex expert team composed by "double-quality supervisors" is established.

\subsubsection{Supervisor's responsibility and function}

In the whole training process of graduate students, the social role of practice bases (enterprises) must be fully played, so that they can play an industry navigation effect in practice and make the standards for industrial personnel. Meanwhile, a latest training goal must be determined in the communication with enterprises. In the process of teaching, enterprise design personnel, technical personnel, and management personnel can be introduced to join; in the curriculum system construction and teaching content reform, a diversified information feedback mechanism between colleges and enterprises must be further enhanced, so as to fundamentally lay an important foundation for solving the problems of divorced school education and social demand, shortening the distance between schools and society in personnel training and demand, and promoting the joint training of graduate students.

\subsection{The management of supervisor team}

\subsubsection{Making a sound supervisor selection system}

The selection of supervisors must be based on the supervisor post demanded by the disciplinary development. Then, a strict recruiting and selecting standard and flexible selection mechanism must be formulated, so as to provide quantitative requirements for supervisors in 
personal scientific research ability, academic level and scientific research projects, and also reasonably collocate the post title structure, age structure, academic degree structure, and edge structure. The number and proportion of the senior scientific research personnel, engineering and technical personnel, and management personnel from off-campus practice bases (enterprises) as supervisors must strictly comply with the requirements proposed by the National Education Steering Committee for professional degree graduate students. The experts or technicians with both solid theoretical foundation and strong practice ability can be employed as off-campus joint training supervisors, so as to establish a school-enterprise joint training model.

4.3.2 Establishing an effective evaluation system and incentive mechanism

The evaluation on supervisors emphatically lies in the whole process of graduate student training, so a scientific, reasonable and operable evaluation index system must be made for improving the mechanism to monitor and manage supervisor teams. Different evaluation standards must be taken to evaluate the supervisors in schools and off-campus practice bases. Supervisors are required to actively participate in a series of processes such as making evaluation index system and reporting evaluation result feedback. Evaluation index system must be established mainly from the perspectives of student training, such as the quality and quantity of papers released by graduate students, the number and level of competitions joined by graduate students, the standardization and quality of the graduation thesis, reviews, achievements in outstanding graduation thesis, employment, and the number of graduate students admitted by $\mathrm{PhD}$ programs. Meanwhile, an innovation oriented education resource allocation and scientific research reward incentive mechanism can be constructed to fully arouse the enthusiasm of supervisors for subject construction, generate a competition mechanism, and help them better develop and perfect themselves.

\section{Conclusion}

Under the school-enterprise joint training model, the social role and practical navigation effect of enterprises must be fully played in practice. It is necessary to consistently regulate and allocate resources, commonly make a training plan for professional degree graduate students and guide them to study and make scientific research. Thus, graduate students can be promoted to possess scientific research ability, practice ability and innovation ability to some extent and become the talents really demanded by the society, to better meet the needs of the social development.

\section{Acknowledgment}

This paper financially aided by the Graduate Educational Reform Project of Lanzhou Jiaotong University, "the Construction of the Guidance Model Joint by Multiple Supervisors for Training the Graduate Students Majoring in Road Landscape Design".

\section{References}

[1] Shou-ting ZHANG, Hanxing LIU, Liqing ZHANG, Lifeng WANG, Hongde HUANG, Zhixiang YUAN. Graduate cultivation mechanism reform and innovation research $[\mathrm{J}]$. Journal of the National Education Administration Institute, 2010, (6): 53 57.

[2] Pei-hua XU, Zhi-cheng ZHONG. Discussion on the Multi-instructor for the Cultivation of Graduates-Enlightenment from the Graduate Student Training of the University of Mississippi [J].

[3] Journal of Higher Building Education, 2013, 22 (4): 34 36. 
[4] Ze-ju LUO. Study on Instructor Team Instructing Model Design and Management in the Cultivation of Graduates [J]. Journal of Chongqing University (Natural Science Edition), 2012, (11): 99 103.

[5] Yanmei XU. Exploration on the Degree Education of Art and Design Graduate Students [J]. Journal of Xiangtan Normal University (Social Science Edition), 2007, (1): 139 140.
[6] Bin-yi LIU, Min WANG. Future-oriented diversified LA Education System-Tongji University Landscape Architecture and Landscape Graduate Student Education Development and Outlook (Vol.7) [J]. Journal of Nanjing Forestry University (Humanities and Social Science Edition), 2007, (12): 11 15. 